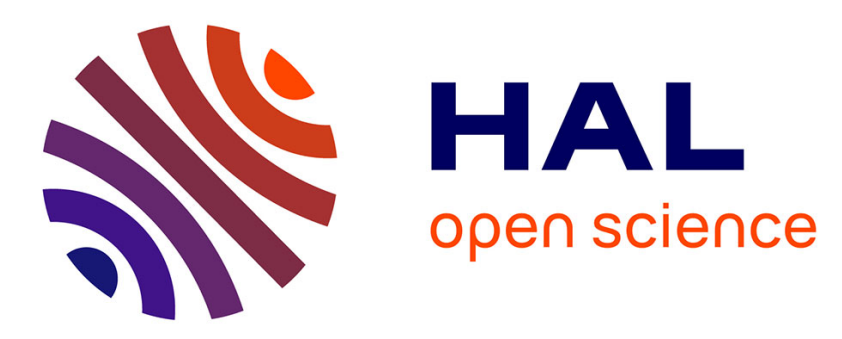

\title{
Kinetic and chemical characterization of aldehyde oxidation by fungal aryl-alcohol oxidase
}

Patricia Ferreira, Aitor Hernández-Ortega, Beatriz Herguedas, Jorge

Rencoret, Ana Gutiérrez, Maria Jesús Martínez, Jesús Jiménez-Barbero, Milagros Medina, Ángel T. Martínez

\section{To cite this version:}

Patricia Ferreira, Aitor Hernández-Ortega, Beatriz Herguedas, Jorge Rencoret, Ana Gutiérrez, et al.. Kinetic and chemical characterization of aldehyde oxidation by fungal aryl-alcohol oxidase. Biochemical Journal, 2010, 425 (3), pp.585-593. 10.1042/BJ20091499 . hal-00479261

\section{HAL Id: hal-00479261 https://hal.science/hal-00479261}

Submitted on 30 Apr 2010

HAL is a multi-disciplinary open access archive for the deposit and dissemination of scientific research documents, whether they are published or not. The documents may come from teaching and research institutions in France or abroad, or from public or private research centers.
L'archive ouverte pluridisciplinaire HAL, est destinée au dépôt et à la diffusion de documents scientifiques de niveau recherche, publiés ou non, émanant des établissements d'enseignement et de recherche français ou étrangers, des laboratoires publics ou privés. 


\title{
Kinetic and chemical characterization of aldehyde oxidation by fungal aryl-alcohol oxidase
}

\author{
Patricia FERREIRA*†, Aitor HERNÁNDEZ-ORTEGA*, Beatriz HERGUEDAS $\dagger$, Jorge \\ RENCORET $\$ 1$, Ana GUTIÉRREZ $\$$, María Jesús MARTÍNEZ*, Jesús JIMÉNEZ-BARBERO*, \\ Milagros MEDINA $\dagger^{2}$ and Ángel T. MARTÍNEZ*2
}

\begin{abstract}
*Centro de Investigaciones Biológicas (CIB), CSIC, Ramiro de Maeztu 9, E-28040 Madrid, Spain, †Departamento de Bioquímica y Biología Molecular y Celular, Facultad de Ciencias, and Instituto de Biocomputación y Física de Sistemas Complejos, Universidad de Zaragoza, E-50009 Zaragoza, Spain, $\ddagger$ Instituto de Recursos Naturales y Agrobiología de Sevilla (IRNAS), CSIC, PO Box 1052, E41080 Seville, Spain
\end{abstract}

\section{Short title: Aldehyde oxidation by aryl-alcohol oxidase}

Fungal aryl-alcohol oxidase (AAO) provides $\mathrm{H}_{2} \mathrm{O}_{2}$ for lignin biodegradation. AAO is active on benzyl alcohols that are oxidized to aldehydes. However, the $\mathrm{H}_{2} \mathrm{O}_{2}$ formed from some of them was more than stoichiometric with respect to the aldehyde detected. This was due to a double reaction that involves aryl-aldehyde oxidase activity. The latter was investigated using different benzylic aldehydes, whose oxidation to acids was demonstrated by GC-MS. The steady and pre-steady state kinetic constants together with the chromatographic results revealed a strong influence of substrate electron withdrawing/donating substituents on activity, being the highest on $p$-nitrobenzaldehyde and halogenated aldehydes and the lowest on methoxylated aldehydes. Moreover, activity was correlated to the aldehyde hydration rates estimated by ${ }^{1} \mathrm{H}-\mathrm{NMR}$. These findings, together with the absence in the AAO active site of a residue able to drive oxidation via an aldehyde thiohemiacetal, suggested that oxidation mainly proceeds via the gem-diol species. The reaction mechanism (with solvent isotope effect of ${ }^{\mathrm{D}_{2} \mathrm{O}} \boldsymbol{k}_{\text {red }} \sim 1.5$ ) would be analogous to that described for alcohols, the reductive half-reaction involving concerted hydride transfer from $\alpha$-carbon, and proton abstraction from one of the gem-diol hydroxyls by a base. The existence of two steps of opposite polar requirements (hydration and hydride transfer) explains some aspects of aldehyde oxidation by AAO. Site-directed mutagenesis identified two histidines strongly involved in gem-diol oxidation and, unexpectedly, suggested that an active-site tyrosine could facilitate the oxidation of some aldehydes showing no detectable hydration. Double alcohol and aldehyde oxidase activities of AAO would contribute to $\mathrm{H}_{2} \mathrm{O}_{2}$ supply by the enzyme.

Key words: Aryl-alcohol oxidase, aromatic aldehydes, gem-diols, enzyme kinetics, GCMS, ${ }^{1} \mathrm{H}-\mathrm{NMR}$

\footnotetext{
${ }^{1}$ Current address: GLBRC, University of Wisconsin-Madison, USA.

2 To whom correspondence should be addressed: A.T. Martínez (email atmartinez@cib.csic.es) and M. Medina (email mmedina@unizar.es).

Abbreviations used: AAO, Aryl-alcohol oxidase; BSTFA, Bis-(trimethylsilyl)-trifluoroacetamide; GMC, Glucose-methanol-choline oxidase; HRP, Horseradish peroxidase.
} 


\section{INTRODUCTION}

Lignin removal is a central process for recycling of the carbon fixed by photosynthesis in land ecosystems, where lignin protects plant polysaccharides against microbial attack, and also represents a central issue in industrial utilization of lignocellulosic biomass for the production of renewable materials, chemicals and fuels in future lignocellulose biorefineries [1]. High redox-potential peroxidases are characteristic of ligninolytic basidiomycetes (the so-called white-rot fungi due to the colour of delignified wood) as recently confirmed by the comparison of fungal genomes [2;3]. Analysis of the currently available white-rot fungal genomes, including those of Phanerochaete chrysosporium and Pleurotus ostreatus, also confirmed the presence of genes of different types of oxidases that are responsible for providing the extracellular $\mathrm{H}_{2} \mathrm{O}_{2}$ required in lignin biodegradation as the peroxidase oxidizing substrate. These include, among others, glyoxal oxidase (EC 1.2.3.5) first reported in $P$. chrysosporium, and aryl-alcohol oxidase (AAO; EC 1.1.3.7) mainly investigated in Pleurotus species [4;5].

Basidiomycetes also produce a variety of extracellular aromatic metabolites that play several roles in lignin degradation [6], and are also of interest for the flavour and finechemical industry as in the case of aromatic aldehydes [7]. Veratryl alcohol is synthesized by $P$. chrysosporium, where it acts as a lignin-peroxidase redox mediator, whereas the Pleurotus versatile peroxidase does not require such a mediator [8]. Therefore, in Pleurotus species the most abundant extracellular metabolite is $p$-anisaldehyde, together with its corresponding acid and alcohol, and some chlorinated metabolites (such as 3chloro-p-anisaldehyde), veratryl alcohol being found only in low levels [9]. It has been shown that the above anisylic compounds are redox cycled, with participation of AAO and myceliar dehydrogenases, resulting in the continuous generation of extracellular $\mathrm{H}_{2} \mathrm{O}_{2}$ for lignin biodegradation at the expense of intracellular reducing power $[9 ; 10]$.

$\mathrm{AAO}$ is an extracellular FAD-containing enzyme in the glucose-methanol-choline oxidase (GMC) oxidoreductase family. It catalyzes the oxidative dehydrogenation of a variety of aromatic (and some aliphatic polyunsaturated) alcohols with an $\alpha$-carbon primary hydroxyl, with the concomitant reduction of $\mathrm{O}_{2}$ to $\mathrm{H}_{2} \mathrm{O}_{2}$ (Fig. 1, top), and its ability to oxidize aromatic aldehydes was also suggested $[11 ; 12]$. AAO was cloned for the first time in Pleurotus eryngii and, after that, has been expressed in Emericella nidulans (conidial state: Aspergillus nidulans) and Escherichia coli for further characterization of the enzyme and its alcohol oxidation mechanism [13-17]. However, to date the aldehyde reaction of AAO remained basically unknown.

In the present work we present the first characterization of aldehyde oxidation by AAO using steady and pre-steady state kinetics of native AAO and some mutated variants. The kinetic studies have been accompanied by GC-MS and NMR analyses of substrates and products to obtain insights on the reaction mechanism of the enzyme.

\section{EXPERIMENTAL}

\section{Chemicals and commercial enzymes}

p-Anisyl, veratryl, $m$ - and $p$-chlorobenzyl, 3-chloro-p-anisyl, $m$ - and $p$-fluorobenzyl alcohols, 2-4-hexadien-1-ol, benzaldehyde, $p$-anisaldehyde, veratraldehyde, $m$ - and $p$ chlorobenzaldehyde, 3-chloro-p-anisaldehyde, $m$ - and $p$-fluorobenzaldehyde, 3,4difluorobenzaldehyde, $p$-nitrobenzaldehyde, 2,4-dinitrobenzaldehyde, 2,4-hexadienal, and benzoic, $p$-anisic, veratric, $m$-chlorobenzoic, 3-chloro- $p$-anisic, and $m$ - and $p$-nitrobenzoic acids were obtained from Sigma-Aldrich (St Louis, MO, USA). Glucose oxidase (from Aspergillus niger; type II) and aldehyde dehydrogenase (from Saccharomyces cerevisiae) were also obtained from Sigma-Aldrich. Amplex ${ }^{\circledR}$ Red was from Invitrogen (Carlsbad, 
CA, USA). Horseradish peroxidase (HRP) was from Roche (Basel, Switzerland). 5-Deazariboflavin was a gift from Dr G. Tollin (University of Arizona, USA).

\section{AAO production}

Recombinant AAO from P. eryngii was obtained by E. coli expression of the mature AAO cDNA (GenBank AF064069) followed by in vitro activation, and purification as previously described [14]. AAO concentrations were determined using the molar absorption coefficient $\left(\varepsilon_{463} 11050 \mathrm{M}^{-1} \cdot \mathrm{cm}^{-1}\right)$.

In addition to the above native (wild-type) AAO, the H502S, H546S and Y92F variants were prepared by PCR using the QuikChange site-directed mutagenesis kit (Stratagene). The cDNA of AAO cloned into the pFLAG1 vector was used as template and the following oligonucleotides, including mutations (underlined) at the corresponding triplets (bold), were used as primers (only direct constructions are shown):
Y92F
5 ' - GGTCTAGCTCTGTTCACTTCATGGTCATGATGCG - 3 '
H502S
5 ' - GCCAACACGATTTTCAG $\overline{C C}$ CAGTTGGAACGGCC - 3 '
H546S

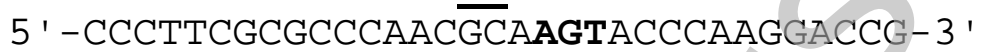

The mutant plasmids were isolated, AAO $\overline{c D N A}$ was sequenced (GS-FLX sequencer from Roche) to confirm that only the designed mutations were introduced, and the variants were produced as indicated above for native AAO.

\section{Steady-state studies}

Steady-state kinetic constants for AAO aldehyde oxidation were calculated by $\mathrm{H}_{2} \mathrm{O}_{2}$ production using a HRP-coupled assay with Amplex ${ }^{B}$ Red at $24{ }^{\circ} \mathrm{C}$ in air-saturated $0.1 \mathrm{M}$ sodium phosphate, $\mathrm{pH}$ 6. Turnover reactions were initiated by addition of AAO with an adder-mixer. In the presence of the $\mathrm{H}_{2} \mathrm{O}_{2}$ generated by AAO, HRP $\left(6 \mathrm{U} \cdot \mathrm{mL}^{-1}\right)$ oxidizes Amplex ${ }^{\circledR} \operatorname{Red}(60 \mu \mathrm{M})$ forming resorufin $\left(\varepsilon_{563} 52000 \mathrm{M}^{-1} \cdot \mathrm{cm}^{-1}\right)$ [18]. After nonlinear fitting of data (3 replicates) using SigmaPlot, mean and standard errors were obtained from the normalized Michaelis-Menten equation. $p$-Nitrobenzaldehyde $(7 \mathrm{mM})$ oxidation by the $\mathrm{H} 502 \mathrm{~S}$ and $\mathrm{H} 546 \mathrm{~S}$ variants and native AAO was also estimated (as turnover numbers).

Oxidation rates of several alcohols by AAO were monitored both by aldehyde formation, using the molar absorbance coefficients [19], and by $\mathrm{H}_{2} \mathrm{O}_{2}$ generation, using a HRP-coupled assay with $O$-dianisidine, at $24{ }^{\circ} \mathrm{C}$ in air-saturated $0.1 \mathrm{M}$ sodium phosphate, $\mathrm{pH}$ 6. Assays were initiated by addition of $\mathrm{AAO}$, and formation of the o-dianisidine oxidation product was monitored $\left(\varepsilon_{460} 6765 \mathrm{M}^{-1} \cdot \mathrm{cm}^{-1}\right)$ [20]. The results were presented as turnover rates $\left(k_{\mathrm{cat}}\right.$ in $\left.\mathrm{s}^{-1}\right)$ obtained as described above.

Moreover, the enzymatic activity of commercial yeast aldehyde dehydrogenase on benzaldehyde, $p$-anisaldehyde and 4-nitrobenzaldehyde was measured in $0.1 \mathrm{M} \mathrm{KCl}, 1 \mathrm{mM}$ EDTA, $0.1 \mathrm{M}$ Tris $\mathrm{HCl}, \mathrm{pH} 8$, at $25{ }^{\circ} \mathrm{C}$, by following the formation of NADH $\left(\varepsilon_{340} 6220\right.$ $\mathrm{M}^{-1} \cdot \mathrm{cm}^{-1}$ ) from $5 \mathrm{mM} \mathrm{NAD}$.

\section{GC-MS studies}

For analyzing the reaction products, $4 \mathrm{mM}$ aldehyde solutions $(1 \mathrm{mM}$ in the cases of $p$ anisaldehyde and 3-chloro-p-anisaldehyde due to solubility constraints) were incubated with AAO $(0.3 \mu \mathrm{M})$ in $0.1 \mathrm{M}$ phosphate, $\mathrm{pH}$ 6. After $3 \mathrm{~h}$ at $24{ }^{\circ} \mathrm{C}$, under shaking, the reaction mixtures were acidified ( $\mathrm{pH}$ 2-3) and liquid-liquid extracted with methyl tert-butyl ether. Extracts were evaporated to dryness and redissolved in chloroform. GC-MS analyses were performed directly or after silylation with bis(trimethylsilyl)trifluoroacetamide (BSTFA) in the presence of pyridine. A Varian Star 3400 chromatograph equipped with a DB-5HT column (30 $\mathrm{m} \times 0.25 \mathrm{~mm}$ i.d., and $0.1 \mu \mathrm{m}$ film thickness) and coupled to an ion- 
trap detector (Varian Saturn 2000 model) was used. The oven was programmed from $50{ }^{\circ} \mathrm{C}$ to $330{ }^{\circ} \mathrm{C}$ at $6{ }^{\circ} \mathrm{C} \cdot \mathrm{min}^{-1}$, and held for $3 \mathrm{~min}$. Both the temperature of the injector and the transfer line were $300^{\circ} \mathrm{C}$. Helium was used as the carrier gas at a flow rate of $2 \mathrm{~mL} \cdot \mathrm{min}^{-1}$. Compounds were identified by comparing their mass spectra with standards, which were also used to obtain response factors.

\section{NMR spectroscopy}

The hydration rates of aldehyde solutions $(\sim 10 \mu \mathrm{M})$ in $0.1 \mathrm{M}$ phosphate, $\mathrm{pH} 6$, prepared with $\mathrm{D}_{2} \mathrm{O}$ (isotopic purity $99.9 \%$ ) was estimated by ${ }^{1} \mathrm{H}-\mathrm{NMR}$ using a Bruker Avance 500$\mathrm{MHz}$ instrument. The signal of residual water proton $\left(\delta_{\mathrm{H}} 4.701 \mathrm{ppm}\right)$ was used as internal reference for chemical shifts. For hydration rate estimation, the signal of the $\mathrm{H}-\mathrm{C}-(\mathrm{OH})_{2}$ proton in the gem-diol species was integrated and referred to that of the $\underline{\mathrm{H}}-\mathrm{C}=\mathrm{O}$ proton of the aldehyde species. Spectra in DMSO (isotopic purity $>99.8 \%$ ) were run as reference, showing only the non-hydrated aldehyde.

\section{Stopped-flow measurements}

Stopped-flow experiments were carried out on an Applied Photophysics SX17.MV spectrophotometer interfaced with an Acorn computer using the SX18.MV and Xscan softwares (from Applied Photophysics). Enzyme-monitored turnover experiments [21], as well as analysis of the reductive half-reactions under anaerobic conditions, were performed as described previously [17] in $0.1 \mathrm{M}$ phosphate, $\mathrm{pH} 6$, at $24{ }^{\circ} \mathrm{C}$. Deconvolution of spectral data was performed by global analysis and numerical integration methods using the Pro-K software (Applied Photophysics Ltd.).

For accurate estimation of observed rate constants $\left(k_{o b s}\right)$ kinetic traces were recorded at $462 \mathrm{~nm}$. These traces were fit into standard double-exponential or mono-exponential decays. $k_{\mathrm{obs} 1}$ and $k_{\mathrm{obs} 2}$ are the observed rate constants for fast and slow phases of the reduction of the enzyme, respectively. The $k_{\mathrm{obs}}$ values at different substrate concentrations were fit to either equation 1 or 2 ,

$$
\begin{aligned}
& k_{o b s}=\frac{k_{r e d} A}{K_{d}+A}(\text { Eq. 1) } \\
& k_{o b s}=\frac{k_{r e d} A}{K_{d}+A}+k_{r e v} \text { (Eq. 2) }
\end{aligned}
$$

where $K_{\mathrm{d}}$ is the dissociation constant for the enzyme-substrate complex, and $k_{\text {red }}$ and $k_{\text {rev }}$ are the limiting rate and reverse rate of flavin reduction.

Solvent isotope effect in the reductive half-reaction of AAO with $p$-nitrobenzaldehyde was determined by measuring rate constants using $\mathrm{H}_{2} \mathrm{O}$ and $\mathrm{D}_{2} \mathrm{O}$. For assays in deuterated solvent, the reaction components were dissolved in deuterated $0.1 \mathrm{M}$ phosphate, $\mathrm{pD} 6$. AAO was exhaustively dialyzed against the deuterated buffer to remove all exchangeable protons.

\section{Spectral characterization of AAO-acid complexes}

Binding of aromatic acids was studied in $0.1 \mathrm{M}$ sodium phosphate, $\mathrm{pH}$. The dissociation constants $\left(K_{\mathrm{d}}\right)$ for the complex of AAO with $p$-anisic acid and 3-chloro-p-anisic acid were determined from the absorption spectra during enzyme titration using the equation 3 for a $1: 1$ stoichiometry,

$$
\Delta A b s=\frac{\Delta \varepsilon\left(E+L+K_{d}\right)-\Delta \varepsilon \sqrt{\left(E+L+K_{d}\right)^{2}-4 E L}}{2}
$$


where $\triangle \mathrm{Abs}$ is the absorbance difference values, $\mathrm{E}$ and $\mathrm{L}$ are the enzyme and ligand concentration, respectively, and $K_{\mathrm{d}}$ is the dissociation constant [22]. Finally, the complex of reduced AAO with $p$-anisic acid was prepared by photoreduction in the presence of EDTA and 5-deazariboflavin, as described previously [23].

\section{RESULTS}

\section{Aldehyde oxidase activity during alcohol oxidation by AAO}

The ability of AAO to continue oxidizing some aldehydes was deduced from the curves of $\mathrm{H}_{2} \mathrm{O}_{2}$ and aldehyde generated during reactions with eight aromatic alcohols (Fig. 2). With $p$-anisyl alcohol, the two curves were similar and the final concentrations corresponded to the initial concentration of the alcohol, in agreement with the reaction stoichiometry (Fig. 1, top). However, with 3-chloro-p-anisyl alcohol the $\mathrm{H}_{2} \mathrm{O}_{2}$ concentration was nearly doubling that of 3-chloro-p-anisaldehyde, suggesting that a fraction of the aldehyde formed was further oxidized releasing extra $\mathrm{H}_{2} \mathrm{O}_{2}$. Simultaneous alcohol oxidase and aldehyde oxidase activities were also produced in the reactions of AAO with other alcohols, e.g. with $m$ - and $p$-fluorobenzyl alcohols (Table 1).

\section{Steady-state kinetics with aldehydes}

To characterize the aldehyde oxidase activity of AAO, a substrate specificity profile was constructed by determining apparent steady-state kinetic parameters with nine para and meta substituted benzylic aldehydes, benzaldehyde and 2,4-hexadienal (Table 2). The activity on 2,4-dinitrobenzaldehyde was too low ( $<1 \%$ that on $p$-nitrobenzaldehyde) to estimate kinetic constants (its water solubility was also low). Considering the AAO efficiency values, $m$-chlorobenzaldehyde was the best aldehyde substrate, while veratraldehyde was the worst substrate. AAO showed the highest $k_{\text {cat }}$ on $p$ nitrobenzaldehyde, while the three methoxylated benzaldehydes showed the lowest $k_{c a t}$ values. Despite its low activity, AAO showed the highest affinity for $p$-anisaldehyde and 3chloro-p-anisaldehyde.

Aldehyde oxidation was also investigated for three AAO variants obtained by sitedirected mutagenesis of two histidine (His502 and His546) and one tyrosine (Tyr92) residues conserved in the active sites of $\mathrm{AAO}$ and glucose oxidase [12]. The two histidines seemed to be crucial for AAO oxidation of aldehydes, since the activities of the H502S and $\mathrm{H} 546 \mathrm{~S}$ variants on saturating concentration of $p$-nitrobenzaldehyde were $0.22 \pm 0.02 \mathrm{~min}^{-1}$ and $0.11 \pm 0.01 \mathrm{~min}^{-1}$, respectively, compared with $75.00 \pm 0.16 \mathrm{~min}^{-1}$ activity of the native enzyme (their low activities prevented estimation of kinetic constants). On the other hand, removal of the phenolic hydroxyl of Tyr92 affected differently oxidation of $p$-anisaldehyde and $p$-nitrobenzaldehyde (Table 3).

\section{GC-MS identification of products from aldehyde oxidase activity}

The products of the reactions of twelve aldehydes with AAO were analyzed by GC-MS directly and after silylation, as illustrated in Fig. 3 for the $p$-nitrobenzaldehyde reaction. The mass spectra of the product peaks revealed formation of $p$-nitrobenzoic acid by AAO. The corresponding acids were also found in the reactions of AAO with most of the aldehydes (Supplementary data in Table S1 provides the characteristic MS fragments, and the quantification of the acids formed). Under the reaction conditions used, the highest oxidation rates were obtained for $p$-chlorobenzaldehyde (48\%), p-nitrobenzaldehyde (43\%) and $m$-chlorobenzaldehyde (39\%), followed by $p$-fluorobenzaldehyde $(20 \%)$ and $p$ anisaldehyde (17\%), no acids were detected from veratraldehyde and 2,4- 
dinitrobenzaldehyde, and low oxidation rates $(<7 \%)$ were obtained after incubation of the other five aldehydes with AAO.

\section{NMR analysis of the gem-diol forms of the aldehyde substrates}

To investigate the possible involvement of the gem-diol species in aldehyde oxidation, the hydration rates of the twelve aldehydes used as AAO substrates were estimated from their ${ }^{1} \mathrm{H}-\mathrm{NMR}$ spectra (Fig. 4). The $p$-anisaldehyde spectrum showed only four signals (plus the residual water signal) corresponding to the methoxy, ortho $\left(\mathrm{H}_{2+6}\right)$ and meta $\left(\mathrm{H}_{3+5}\right)$, and aldehyde $\left(\mathrm{H}_{\alpha}\right)$ protons. The absence of the gem-diol benzylic proton signal $\left(\delta_{\mathrm{H}} 6 \mathrm{ppm}\right)$ indicated that $p$-anisaldehyde was not hydrated. On the other hand, the $p$ nitrobenzaldehyde spectrum included the gem-diol signal $\left(\mathrm{H}_{\alpha^{\prime}}\right)$ together with that of the aldehyde form $\left(\mathrm{H}_{\alpha}\right)$, as well as double signals for the ring protons for both the gem-diol $\left(\mathrm{H}_{2^{\prime}+6^{\prime}}\right.$ and $\left.\mathrm{H}_{3^{\prime}+5^{\prime}}\right)$ and the aldehyde $\left(\mathrm{H}_{2+6}\right.$ and $\left.\mathrm{H}_{3+5}\right)$ species, revealing partial hydration. Similar gem-diol signals were detected in all the other NMR spectra, with the panisaldehyde and veratraldehyde exceptions, and the hydration rates were obtained by integrating the benzylic proton $\left(\mathrm{H}_{\alpha^{\prime}}\right.$ and $\left.\mathrm{H}_{\alpha}\right)$ signals (the chemical shifts, and the hydration rates obtained are shown in Table S2).

The hydration rates of all the aldehydes assayed were relatively modest with the only exception of 2,4-dinitrobenzaldehyde. The highest values were obtained for the aromatic aldehydes bearing electron-withdrawing substituents, which facilitated the hydration reaction when located at ortho or para positions, such as one or two nitro groups ( $20 \%$ and $83 \%$ hydration, respectively), or at meta position, such as chlorine $(4 \%)$ or fluorine $(3 \%)$ atoms. The presence of halogen atoms at para position did not increase hydration with respect to benzaldehyde (1\%), as expected from the above mentioned meta orientation of their electron-withdrawing effect, and the same was observed when comparing the hydration rates of 3,4-difluorobenzaldehyde and $m$-fluorobenzaldehyde (both being 3\%). On the contrary, the presence of methoxy substituents, acting as electron donors, especially at para position, resulted in the complete absence of the gem-diol form, as found for $p$ anisaldehyde and veratraldehyde. Finally, the aliphatic polyunsaturated 2,4-hexadienal showed a very low hydration rate (below $1 \%$ ).

\section{Oxidation of benzylic aldehydes by yeast aldehyde dehydrogenase}

The possible influence of different ring-substituents on aromatic aldehyde oxidation by an enzyme that does not oxidize the gem-diol forms but acts on the non-hydrated aldehydes was investigated. Interestingly, although the catalytic efficiency of aldehyde dehydrogenase oxidizing benzaldehyde was higher than on $p$-anisaldehyde, it was not further increased by the presence of an electron withdrawing substituent in $p$ nitrobenzaldehyde (see Supplementary data in Fig. S1) as found with AAO.

\section{Stopped-flow spectrophotometric studies}

By monitoring the redox state of the cofactor during AAO catalysis, information was obtained about the rate-limiting step. Using $p$-nitrobenzaldehyde as substrate, it was found that the enzyme is fully oxidized under air-saturated steady-state conditions (Fig. 5). These corresponded to the first 1-2 min of reaction (Fig. 5, inset) when $\mathrm{O}_{2}$ is not limitant yet, and indicated that the reductive half-reaction by the aldehyde is much slower than the oxidative half-reaction by $\mathrm{O}_{2}$.

Pre-steady state reduction of the oxidized enzyme by $p$-anisaldehyde, 3-chloro-panisaldehyde, veratraldehyde and $p$-nitrobenzaldehyde was investigated under anaerobic conditions (Figs. 6 and S2). The first spectra obtained after mixing AAO with the different 
aldehydes (dotted curves) were in general different from those observed in the absence of substrate (dashed curves), showing displacement of the main flavin band (462 nm), and increased absorbance. These changes reflected formation of the oxidized-enzyme complex with the aldehyde substrate $\left(\mathrm{AAO}_{\mathrm{ox}}-\mathrm{S}\right)$. The subsequent decrease at $462 \mathrm{~nm}$ corresponded to the reductive half-reaction. Formation of a charge-transfer complex between the reduced enzyme and the product $\left(\mathrm{AAO}_{\mathrm{red}} \mathrm{-P}\right)$, characterized by a peak at $490 \mathrm{~nm}$ and a longwavelength band, was also observed in the $p$-anisaldehyde (Fig. 6a), 3-chloro-panisaldehyde and veratraldehyde (Fig. S2) reactions. The spectral course of the reductive half-reaction fit to an irreversible two-step process without formation of any intermediate species for $p$-anisaldehyde, 3-chloro-p-anisaldehyde and veratraldehyde (with rate constants at saturating substrate concentration of $1.32,0.76$ and $0.18 \mathrm{~min}^{-1}$, respectively) (Figs. 6a and S2). However, AAO reduction by $p$-nitrobenzaldehyde best fit a three-step process (Fig. 6b), its initial phase (over $90 \mathrm{~min}^{-1}$ rate constant) being considerably faster than the reduction by the other aldehyde substrates (Fig. 6c). The dependence of $k_{\text {obs }}$ on aldehyde concentration was determined with $p$-nitrobenzaldehyde (that showed $20 \%$ hydration and the highest turnover) and $p$-anisaldehyde (that showed low reactivity and no detectable $g e m$-diol). These $k_{\text {obs }}$ dependences exhibited hyperbolic saturation profiles with good fit to Eq. 1, suggesting an essentially irreversible flavin reduction and allowing the determination of transient constants for $p$-anisaldehyde $\left(k_{\text {red }} 1.5 \pm 0.2 \mathrm{~min}^{-1}\right.$, and $K_{\mathrm{d}} 0.032 \pm$ $0.019 \mathrm{mM})$ and $p$-nitrobenzaldehyde $\left(k_{\mathrm{red}} 356 \pm 38 \mathrm{~min}^{-1}\right.$, and $\left.K_{\mathrm{d}} 05.79 \pm 00.77 \mathrm{mM}\right) . \mathrm{In}$ the case of $p$-nitrobenzaldehyde, AAO reduction is completed in a second slow phase $\left(k_{\text {red }}\right.$ $\sim 0.74 \mathrm{~min}^{-1}$ ).

Using deuterated buffer, a solvent isotope effect with a ${ }^{\mathrm{D}_{2} \mathrm{O}} k_{\text {red }}$ value of 1.5 (representing the ratio between $k_{\text {red }}$ in $\mathrm{H}_{2} \mathrm{O}$ and in $\mathrm{D}_{2} \mathrm{O}$ ) was observed in the fast process of the AAO reductive half-reaction with $p$-nitrobenzaldehyde.

\section{Spectral characterization of AAO complexes with aromatic acids}

It was found that aromatic acids bind on AAO modifying its absorption spectrum (as illustrated in Fig. S3a for AAO titration with 3-chloro- $p$-anisic acid). Qualitatively similar difference spectra were also obtained with $p$-anisic, veratric, $m$-chlorobenzoic, $m$ fluorobenzoic and benzoic acids (data not shown). The tightest binding was observed with 3-chloro- $p$-anisic acid and $p$-anisic acid resulting in $K_{\mathrm{d}}$ of $31.5 \pm 0.1 \mu \mathrm{M}$ and $94 \pm 3 \mu \mathrm{M}$, respectively. The low AAO affinity for the other acids suggested $K_{d}$ values in the $\mathrm{mM}$ range. The spectrum of the $\mathrm{AAO}_{\text {red }}(p$-anisic acid) complex (Fig. S3b) was obtained by photoreduction of the $\mathrm{AAO}_{\mathrm{ox}}$-( $p$-anisic acid) complex. It was characterized by the displacement of the flavin maximum to $\sim 490 \mathrm{~nm}$ and the absorbance in the $520-600 \mathrm{~nm}$ region, being similar to that observed at the end of the stopped-flow experiments with $p$ anisaldehyde. This indicated that the fully-reduced species observed after AAO reduction with this aldehyde, as well as with 3-chloro-p-anisaldehyde, is the $\mathrm{AAO}_{\text {red-acid complex }}$ (Fig. 6a and b). The other acids showed much looser binding and, therefore, no AAO red $^{-}$ acid complexes were detected at the end of AAO reduction (Fig. S2).

\section{DISCUSSION}

\section{Aldehyde oxidase activity of AAO: Aldehyde hydration and enzymatic oxidation}

AAO typically oxidizes aromatic alcohols to the corresponding aldehydes, with the concomitant production of $\mathrm{H}_{2} \mathrm{O}_{2}$ [11;19] (Fig. 1, top). We demonstrated here the ability of the enzyme to continue the oxidation of some alcohols up to the corresponding acids, confirming ${ }^{19}$ F-NMR preliminary results [19]. The aldehyde oxidase activity of AAO was confirmed by the mass spectra of the acids formed from a variety of aldehydes. The GC- 
MS results were in good agreement with the $k_{\text {cat }}$ values obtained, $p$-nitrobenzaldehyde and two chlorobenzaldehydes appearing as the best AAO substrates in both cases.

In water solution, carbonyl compounds exist in equilibrium with their gem-diol forms. The hydration rates of the aromatic aldehydes are generally low compared with the aliphatic ones, and that of benzaldehyde is often considered as negligible. However, using ${ }^{1} \mathrm{H}-\mathrm{NMR}$ we demonstrated that all the aldehydes studied presented detectable hydration rates, with the exception of veratraldehyde and $p$-anisaldehyde. These could be correlated to the presence of electron withdrawing/donating substituents that stabilize/destabilize the gem-diol form.

Enzymatic oxidation of aldehydes is often produced at their unhydrated form with contribution from an active site residue forming a covalent adduct that favours oxidation. The most classical example are aldehyde dehydrogenases, where a cysteine forms a thiohemiacetal linkage with the aldehyde substrate [24]. Active-site serine, glutamate or lysine residues could also activate aldehydes by forming adducts under specific conditions [25]. Alternatively, active-site metals can promote in situ hydration, as suggested for benzaldehyde oxidation by horse liver alcohol dehydrogenase [26] and mammalian aldehyde oxidases [27]. In the AAO active-site structure (PDB entry 3FIM) no residues susceptible of forming aldehyde adducts are present, and the enzyme does not contain metals [16]. This, together with the observed correlation between the oxidation and the hydration rates of aldehydes, suggested that water would be the activating molecule in aldehyde oxidation by AAO (Fig. 1, bottom). Oxidation of hydrated aldehydes has been reported for histidinol dehydrogenase [25], two mutated aldehyde dehydrogenases [28;29], and choline oxidase [30]. Moreover, a positive correlation between aldehyde hydration and oxidation rates has also been found for Drosophila melanogaster alcohol oxidase [31]. The similar activities obtained for benzaldehyde and $p$-nitrobenzaldehyde oxidation by yeast aldehyde dehydrogenase contrasted with those found with AAO, and supported different oxidation mechanisms by both enzymes.

The aldehyde oxidase activity of AAO is low compared with its alcohol oxidase activity [19]. However, when the variable hydration rates were taken into account, the highest activity corresponded to the gem-diols of $m$-fluorobenzaldehyde, $p$-fluorobenzaldehyde and $p$-chlorobenzaldehyde, their corrected $k_{\text {cat }}$ values $\left(100-130 \mathrm{~s}^{-1}\right)$ being close to those obtained for the best alcohol substrates of AAO [17].

\section{Mechanisms of aldehyde oxidation by AAO}

If, as suggested above, the preferred aldehyde substrates of AAO are the gem-diol forms, coexisting with the carbonyl ones, the mechanism of the rate-limiting reductive halfreaction would probably be similar to that recently reported for AAO oxidation of alcohols, characterized by the concerted transfer of $\alpha$-carbon hydride to flavin and hydroxyl proton to a catalytic base [17]. The very slow AAO oxidation of 2,4-dinitrobenzaldehyde (despite of its high hydration rate) can be explained because, once hydration has been promoted by the two nitro groups, their electron withdrawing action will make difficult the hydride transfer. A similar situation was reported for oxidation of chlorinated acetaldehyde gemdiols by $D$. melanogaster alcohol dehydrogenase [31].

Cleavage of one of the gem-diol $\mathrm{O}-\mathrm{H}$ bonds would involve an active site histidine acting as a base, as suggested for conserved His502 or His546 (Fig. 9) in alcohol oxidation by AAO [32]. This was confirmed by the H502S and H546S variants, which showed much lower activities on $p$-nitrobenzaldehyde than the native enzyme. The 340 -fold activity decrease of H502S was in the range of that reported for $p$-anisyl alcohol oxidation [33], but that of H546S (670 folds) was higher than reported for alcohol oxidation (10 folds) [33] 
indicating that this residue plays a more important role in oxidation of gem-diols than alcohols by AAO.

A concerted cleavage of gem-diol C-H and $\mathrm{O}-\mathrm{H}$ bonds is suggested by the solvent kinetic isotope effect for AAO reduction by $p$-nitrobenzaldehyde $\left({ }^{\mathrm{D}_{2} \mathrm{O}} k_{\text {red }} 1.5\right)$, which was similar to that reported for its reduction by p-anisyl alcohol and 2,4-hexadien-1-ol [17]. The above AAO oxidation mechanism contrasts with the sequential mechanism, involving previous alcohol activation to the alkoxide without a detectable solvent isotope effect, reported for choline oxidase [34;35].

Substitution of Tyr92, located over the AAO flavin ring (Fig. S4), by a phenylalanine residue did not strongly affect the oxidation of $p$-nitrobenzaldehyde, in agreement with alcohol oxidation results [32]. However, the Y92F mutation caused 5-fold reduction of the $p$-anisaldehyde $k_{\text {cat }}$, suggesting that the phenolic hydroxyl would exert some effect in the activation of aldehydes that are not spontaneously hydrated. Alternatively, Tyr92 could promote the oxidation of a minor gem-diol form, below the detection level of ${ }^{1} \mathrm{H}-\mathrm{NMR}$. Oxidation of minute mole fractions of preformed gem-diol and enzyme-aided hydration have been proposed as two alternative hypothesis to explain aldehyde oxidation by some alcohol dehydrogenases [26;36] and histidinol dehydrogenase [37].

\section{AAO is a versatile oxidase providing $\mathrm{H}_{2} \mathrm{O}_{2}$ for lignin degradation}

A difference between AAO and other oxidases/dehydrogenases catalyzing oxidation of alcohols to acids concerns the eventual release of the aldehyde intermediates. Since the specific reaction catalyzed by choline oxidase is the conversion of choline into glycine betaine, the intermediate betaine aldehyde is not release from the enzyme under physiological conditions (although the enzyme is able to oxidize it when exogenously added) [38]. The same occurs in the histidinol dehydrogenase reaction [37]. In contrast, the physiological role of AAO is generation of extracellular $\mathrm{H}_{2} \mathrm{O}_{2}$, in a double redox-cycle (alcohol $\leftrightarrow$ aldehyde and aldehyde $\leftrightarrow$ acid) where the oxidation products are not incorporated to metabolic pathways but reduced back by mycelium-associated dehydrogenases, for the continuous supply of the peroxide required in lignin biodegradation [10;39].

Interestingly, those basidiomycetes producing AAO, typically Pleurotus and Bjerkandera species [11;40], also synthesize methoxylated and halogenated aromatic compounds, which can be detected in the extracellular medium (as alcohols, aldehydes and/or acids) [9;41]. $p$-Anisylic and 3-chloro- $p$-anisylic compounds are among the most abundant Pleurotus [9] and Bjerkandera [42;43] metabolites. On the other hand, although few nitroaromatics are synthesized by basidiomycetes compared with the extended production of haloaromatics [44], $p$-nitrobenzaldehyde biosynthesis has been reported [45] and $p$-nitrosalicylic acid was very recently found in Pleurotus cultures (Giovanni Sannia personal communication). It seems that AAO has evolved to use differently substituted benzylic metabolites for $\mathrm{H}_{2} \mathrm{O}_{2}$ production. Depending of the compound available, AAO will behave basically as an alcohol oxidase (e.g. in the presence of veratrylic and anisylic metabolites), as an aldehyde oxidase (e.g. in the presence of p-nitrobenzylic metabolites) or as a double oxidase being able to transform alcohols into the corresponding acids (e.g. in the presence of 3-chloro-p-anisylic metabolites) (Fig. 1, top, bottom and top+bottom, respectively). This substrate versatility would help AAO to provide a maximal supply of $\mathrm{H}_{2} \mathrm{O}_{2}$ for lignin biodegradation under variable physiological and environmental conditions. 


\section{Acknowledgements}

The authors thank Antonio Romero (CIB, CSIC, Madrid) for providing access to the AAO crystal structure. P.F. thanks a "Juan de la Cierva" contract of the Spanish Ministry of Science and Innovation, and J.R. thanks a I3P Fellowship of the CSIC.

\section{Funding}

This work was supported by the Spanish Biotechnology Programme [grants numbers BIO2007-65890-C02-01 and BIO2008-01533] and the BIORENEW project of the European Union [grant number NMP2-CT-2006026456].

\section{REFERENCES}

1 Martínez,A.T., Ruiz-Dueñas,F.J., Martínez,M.J., del Río,J.C. and Gutiérrez,A. (2009) Enzymatic delignification of plant cell-wall: From nature to mill. Curr.Opin.Biotechnol., 20, 348-357.

2 Martinez,D., Challacombe,J., Morgenstern,I., Hibbett,D.S., Schmoll,M., Kubicek,C.P., Ferreira,P., RuizDueñas,F.J., Martínez,A.T., Kersten,P., Hammel,K.E., Vanden Wymelenberg,A., Gaskell,J., Lindquist,E., Sabat,G., Bondurant,S.S., Larrondo,L.F., Canessa,P., Vicuña,R., Yadav,J., Doddapaneni,H., Subramanian,V., Pisabarro,A.G., Lavín,J.L., Oguiza,J.A., Master,E., Henrissat,B., Coutinho,P.M., Harris,P., Magnuson,J.K., Baker,S.E., Bruno,K., Kenealy,W., Hoegger,P.J., Kues,U., Ramaiya,P., Lucas,S., Salamov,A., Shapiro,H., Tu,H., Chee,C.L., Misra,M., Xie,G., Teter,S., Yaver,D., James,T., Mokrejs,M., Pospisek,M., Grigoriev,I.V., Brettin,T., Rokhsar,D., Berka,R. and Cullen,D. (2009) Genome, transcriptome, and secretome analysis of wood decay fungus Postia placenta supports unique mechanisms of lignocellulose conversion. Proc.Natl.Acad.Sci.USA, 106, 1954-1959.

3 Martínez,D., Larrondo,L.F., Putnam,N., Gelpke,M.D., Huang,K., Chapman,J., Helfenbein,K.G., Ramaiya,P., Detter,J.C., Larimer,F., Coutinho,P.M., Henrissat,B., Berka,R., Cullen,D. and Rokhsar,D. (2004) Genome sequence of the lignocellulose degrading fungus Phanerochaete chrysosporium strain RP78. Nat.Biotechnol., 22, 695-700.

4 Cullen,D. and Kersten,P.J. (2004) Enzymology and molecular biology of lignin degradation. In Mycota III: Biochemistry and Molecular Biology (Brambl,R. and Marzluf,G.A. Eds.), pp. 249-273. Springer, Berlin.

5 Martínez,A.T., Speranza,M., Ruiz-Dueñas,F.J., Ferreira,P., Camarero,S., Guillén,F., Martínez,M.J., Gutiérrez,A. and del Río,J.C. (2005) Biodegradation of lignocellulosics: Microbiological, chemical and enzymatic aspects of fungal attack to lignin. Intern.Microbiol., 8, 195-204.

6 de Jong,E., Field,J.A. and de Bont,J.A.M. (1994) Aryl alcohols in the physiology of ligninolytic fungi. FEMS Microbiol.Rev., 13, 153-188.

7 Gallois,A., Gross,B., Langlois,D., Spinnler,H.-E. and Brunerie,P. (1990) Influence of culture conditions on production of flavour compounds by 29 ligninolytic basidiomycetes. Mycol.Res., 94, 494-504.

8 Ruiz-Dueñas,F.J. and Martínez,A.T. (2009) Microbial degradation of lignin: How a bulky recalcitrant polymer is efficiently recycled in nature and how we can take advantage of this. Microbial Biotechnol., 2, 164-177.

9 Gutiérrez,A., Caramelo,L., Prieto,A., Martínez,M.J. and Martínez,A.T. (1994) Anisaldehyde production and aryl-alcohol oxidase and dehydrogenase activities in ligninolytic fungi from the genus Pleurotus. Appl.Environ.Microbiol., 60, 1783-1788.

10 Guillén,F. and Evans,C.S. (1994) Anisaldehyde and veratraldehyde acting as redox cycling agents for $\mathrm{H}_{2} \mathrm{O}_{2}$ production by Pleurotus eryngii. Appl.Environ.Microbiol., 60, 2811-2817.

11 Guillén,F., Martínez,A.T. and Martínez,M.J. (1992) Substrate specificity and properties of the aryl-alcohol oxidase from the ligninolytic fungus Pleurotus eryngii. Eur.J.Biochem., 209, 603-611.

12 Varela,E., Martínez,M.J. and Martínez,A.T. (2000) Aryl-alcohol oxidase protein sequence: A comparison with glucose oxidase and other FAD oxidoreductases. Biochim.Biophys.Acta, 1481, 202-208.

13 Varela,E., Martínez,A.T. and Martínez,M.J. (1999) Molecular cloning of aryl-alcohol oxidase from Pleurotus eryngii, an enzyme involved in lignin degradation. Biochem.J., 341, 113-117.

14 Ruiz-Dueñas,F.J., Ferreira,P., Martínez,M.J. and Martínez,A.T. (2006) In vitro activation, purification, and characterization of Escherichia coli expressed aryl-alcohol oxidase, a unique H2O2-producing enzyme. Protein Expr.Purif., 45, 191-199. 
15 Varela,E., Guillén,F., Martínez,A.T. and Martínez,M.J. (2001) Expression of Pleurotus eryngii aryl-alcohol oxidase in Aspergillus nidulans: purification and characterization of the recombinant enzyme.

Biochim.Biophys.Acta, 1546, 107-113.

16 Fernández,I.S., Ruiz-Dueñas,F.J., Santillana,E., Ferreira,P., Martínez,M.J., Martínez,A.T. and Romero,A. (2009) Novel structural features in the GMC family of oxidoreductases revealed by the crystal structure of fungal aryl-alcohol oxidase. Acta Crystallogr.D, 65, 1196-1205.

17 Ferreira,P., Hernández-Ortega,A., Herguedas,B., Martínez,A.T. and Medina,M. (2009) Aryl-alcohol oxidase involved in lignin degradation: A mechanistic study based on steady and pre-steady state kinetics and primary and solvent isotope effects with two different alcohol substrates. J.Biol.Chem., 284, 24802487.

18 Hassan-Abdallah,A., Bruckner,R.C., Zhao,G.H. and Jorns,M.S. (2005) Biosynthesis of covalently bound flavin: Isolation and in vitro flavinylation of the monomeric sarcosine oxidase apoprotein. Biochemistry, 44, 6452-6462.

19 Ferreira,P., Medina,M., Guillén,F., Martínez,M.J., van Berkel,W.J.H. and Martínez,A.T. (2005) Spectral and catalytic properties of aryl-alcohol oxidase, a fungal flavoenzyme acting on polyunsaturated alcohols. Biochem.J., 389, 731-738.

20 Wagner,M.A. and Jorns,M.S. (2000) Monomeric sarcosine oxidase: 2. Kinetic studies with sarcosine, alternate substrates, and a substrate analogue. Biochemistry, 39, 8825-8829.

21 Gibson,Q.H., Swoboda,B.E. and Massey,V. (1964) Kinetics and mechanism of action of glucose oxidase. J.Biol.Chem., 239, 3927-3934.

22 Sancho,J. and Gómez-Moreno,C. (1991) Interaction of ferredoxin-NADP+ reductase from Anabaena with its substrates. Arch.Biochem.Biophys., 288, 231-238.

23 Medina,M., Martínez-Julvez,M., Hurley,J.K., Tollin,G. and Gómez-Moreno,C. (1998) Involvement of glutamic acid 301 in the catalytic mechanism of ferredoxin-NADP+ reductase from Anabaena PCC 7119. Biochemistry, 37, 2715-2728.

24 Marchal,S. and Branlant,G. (1999) Evidence for the chemical activation of essential Cys-302 upon cofactor binding to nonphosphorylating glyceraldehyde 3-phosphate dehydrogenase from Streptococcus mutans. Biochemistry, 38, 12950-12958.

25 Teng,H., Segura,E. and Grubmeyer,C. (1993) Conserved cysteine residues of histidinol dehydrogenase are not involved in catalysis - Novel chemistry required for enzymatic aldehyde oxidation. J.Biol.Chem., 268, $14182-14188$.

26 Olson,L.P., Luo,J., Almarsson,O. and Bruice,T.C. (1996) Mechanism of aldehyde oxidation catalyzed by horse liver alcohol dehydrogenase. Biochemistry, 35, 9782-9791.

27 Garattini,E., Fratelli,M. and Terao,M. (2008) Mammalian aldehyde oxidases: genetics, evolution and biochemistry. Cell.Mol.Life Sci., 65, 1019-1048.

28 Corbier,C., Della,S.F. and Branlant,G. (1992) A new chemical mechanism catalyzed by a mutated aldehyde dehydrogenase. Biochemistry, 31, 12532-12535.

29 Ge,X., Penney,L.C., van de Rijn,I. and Tanner,M.E. (2004) Active site residues and mechanism of UDPglucose dehydrogenase. Eur.J. Biochem., 271, 14-22.

30 Fan,F., Germann,M.W. and Gadda,G. (2006) Mechanistic studies of choline oxidase with betaine aldehyde and its isosteric analogue 3,3-dimethylbutyraldehyde. Biochemistry, 45, 1979-1986.

31 Eisses,K.T. (1989) On the oxidation of aldehydes by alcohol-dehydrogenase of Drosophila melanogaster - Evidence for the gem-diol as the reacting substrate. Bioorg.Chem., 17, 268-274.

32 Ferreira,P., Ruiz-Dueñas,F.J., Martínez,M.J., van Berkel,W.J.H. and Martínez,A.T. (2006) Site-directed mutagenesis of selected residues at the active site of aryl-alcohol oxidase, an $\mathrm{H} 2 \mathrm{O} 2$-producing ligninolytic enzyme. FEBS J., 273, 4878-4888.

33 Hernández,A., Ferreira,P., Martínez,M.J., Romero,A. and Martínez,A.T. (2008) Discriminating the role of His502 and His546 in the catalysis of aryl-alcohol oxidase. In Flavins and flavoproteins 2008 (Frago,S., Gómez-Moreno,C. and Medina,M. Eds.), pp. 303-308. Prensas Universitarias, Zaragoza.

34 Fan,F. and Gadda,G. (2005) On the catalytic mechanism of choline oxidase. J.Am.Chem.Soc., 127, 2067-2074.

35 Gadda,G. (2008) Hydride transfer made easy in the reaction of alcohol oxidation catalyzed by flavindependent oxidases. Biochemistry, 47, 13745-13753.

36 Winberg,J.O. and McKinley-McKee,J.S. (1998) Drosophila melanogaster alcohol dehydrogenase: mechanism of aldehyde oxidation and dismutation. Biochem.J., 329, 561-570. 
37 Barbosa,J.A.R.G., Sivaraman,J., Li,Y.G., Larocque,R., Matte,A., Schrag,J.D. and Cygler,M. (2002) Mechanism of action and $\mathrm{NAD}(+)$-binding mode revealed by the crystal structure of L-histidinol dehydrogenase. Proc.Natl.Acad.Sci U.S A, 99, 1859-1864.

38 Gadda,G. (2003) Kinetic mechanism of choline oxidase from Arthrobacter globiformis. Biochim.Biophys.Acta, 1646, 112-118.

39 Guillén,F., Martínez,A.T., Martínez,M.J. and Evans,C.S. (1994) Hydrogen peroxide-producing system of Pleurotus eryngii involving the extracellular enzyme aryl-alcohol oxidase. Appl.Microbiol.Biotechnol., 41, 465-470.

40 Romero,E., Ferreira,P., Martínez,A.T. and Martínez,M.J. (2009) New oxidase from Bjerkandera arthroconidial anamorph that oxidizes both phenolic and nonphenolic benzyl alcohols. Biochim.Biophys.Acta, 1794, 689-697.

41 de Jong,E., Field,J.A., Spinnler,H.E., Wijnberg,J.B.P.A. and de Bont,J.A.M. (1994) Significant biogenesis of chlorinated aromatics by fungi in natural environments. Appl.Environ.Microbiol., 60, 264-270.

42 de Jong,E., Field,J.A., Dings,J.A.F.M., Wijnberg,J.B.P.A. and de Bont,J.A.M. (1992) De novo biosynthesis of chlorinated aromatics by the white-rot fungus Bjerkandera sp BOS55. Formation of 3chloro-anisaldehyde from glucose. FEBS Lett., 305, 220-224.

43 Spinnler,H.E., de Jong,E., Mauvais,G., Semon,E. and Le Quéré,J.-L. (1994) Production of halogenated compounds by Bjerkandera adusta. Appl.Microbiol.Biotechnol., 42, 212-221.

44 de Jong,E. and Field,J.A. (1997) Sulfur tuft and turkey tail: Biosynthesis and biodegradation of organohalogens by basidiomycetes. Annu.Rev.Microbiol., 51:375-414, 375-414.

45 Thaller,V. and Turner,J.L. (1972) Natural acetylenes. Part XXXV. Polyacetylenic acid and benzenoid metabolites from cultures of the fungus Lepista diemii Singer. J.Chem.Soc.Perkin Trans.1., 2032-2034. 
Table $1 \mathrm{H}_{2} \mathrm{O}_{2}$ and aldehyde production in AAO oxidation of different alcohols

The reactions were conducted at $24^{\circ} \mathrm{C}$ in $0.1 \mathrm{M}$ phosphate, $\mathrm{pH}$ 6. Means and standard errors of turnover numbers (indicating moles of product formed by mole of enzyme in 1 s) are presented.

\begin{tabular}{lcc}
\hline & $\mathrm{H}_{2} \mathrm{O}_{2}\left(\mathrm{~s}^{-1}\right)$ & Aldehyde $\left(\mathrm{s}^{-1}\right)$ \\
\hline$p$-Anisyl alcohol & $106 \pm 5$ & $113 \pm 2$ \\
Veratryl alcohol & $75 \pm 2$ & $88 \pm 1$ \\
$m$-Chlorobenzyl alcohol & $21 \pm 1$ & $21 \pm 1$ \\
$p$-Chlorobenzyl alcohol & $37 \pm 1$ & $33 \pm 1$ \\
3-Chloro-p-anisyl alcohol & $60 \pm 1$ & $39 \pm 1$ \\
$m$-Fluorobenzyl alcohol & $22 \pm 1$ & $15 \pm 1$ \\
$p$-Fluorobenzyl alcohol & $28 \pm 1$ & $20 \pm 1$ \\
2,4-Hexadien-1-ol & $138 \pm 2$ & $135 \pm 2$ \\
\hline
\end{tabular}




\section{Table 2 Steady-state kinetic constants for AAO oxidation of different aldehydes}

Oxidation assays on a variety of aldehyde substrates were performed in $0.1 \mathrm{M}$ sodium phosphate, $\mathrm{pH} 6$, at $24{ }^{\circ} \mathrm{C}$. The kinetics parameters were calculated by $\mathrm{H}_{2} \mathrm{O}_{2}$ production using a HRP-coupled assay. After nonlinear fitting of data, means and standard errors were obtained from the normalized Michaelis-Menten equation.

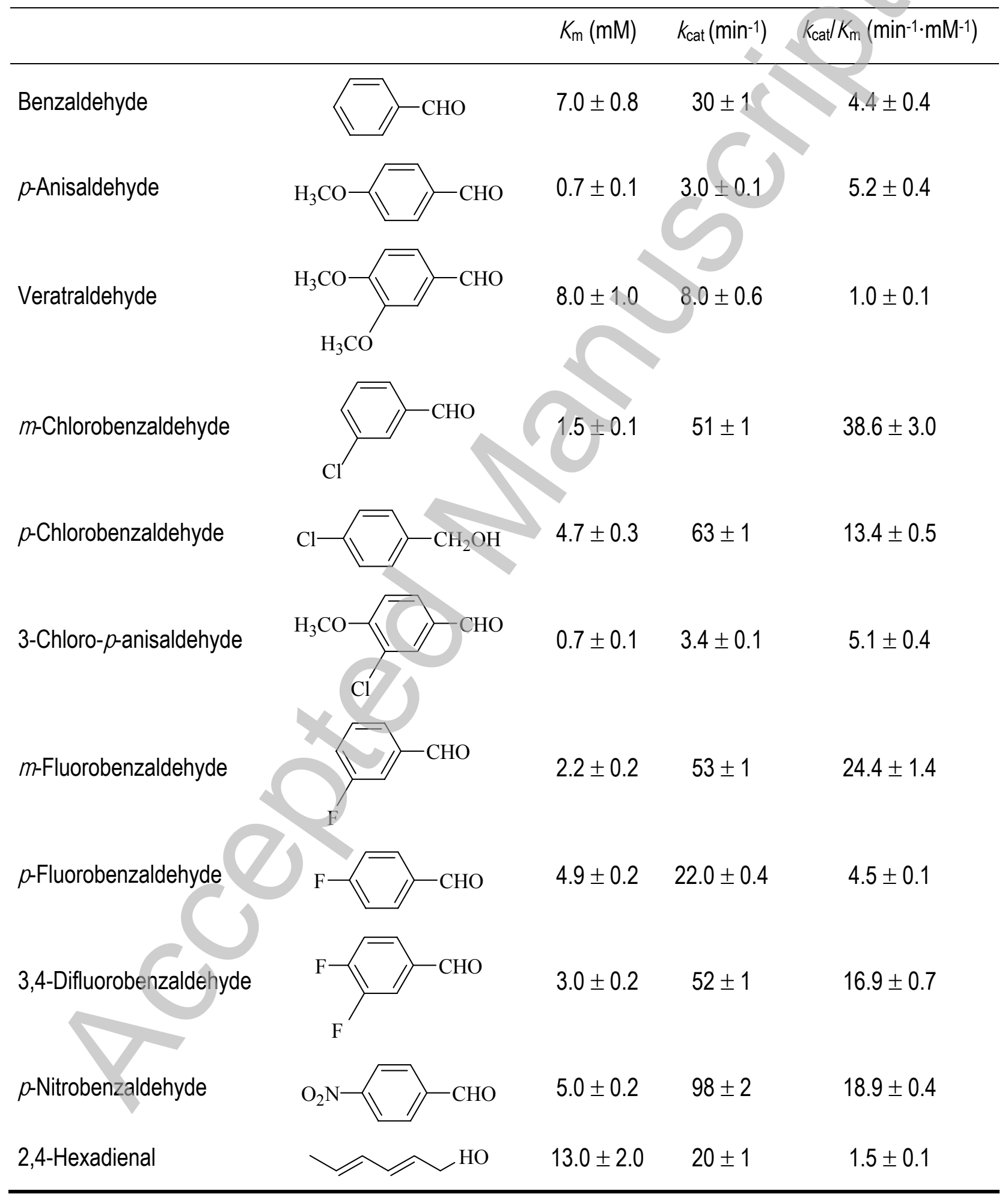


Table 3 Steady-state kinetic constants for oxidation of two aldehydes by the Y92F variant and native AAO

The Y92F kinetic constants were obtained as those for native AAO included in Table 2.

\begin{tabular}{lccc}
\hline & $\begin{array}{c}K_{\mathrm{m}} \\
(\mathrm{mM})\end{array}$ & $\begin{array}{c}k_{\mathrm{cat}} \\
\left(\mathrm{min}^{-1}\right)\end{array}$ & $\begin{array}{c}k_{\mathrm{cat}} / K_{\mathrm{m}} \\
\left(\mathrm{min}^{-1} \cdot \mathrm{mM}^{-1}\right)\end{array}$ \\
\hline $\begin{array}{l}\text { p-Anisaldehyde } \\
\text { Y92F }\end{array}$ & $0.8 \pm 0.1$ & $0.7 \pm 0.02$ & $0.8 \pm 0.03$ \\
$\quad$ Native & $0.7 \pm 0.1$ & $3.0 \pm 0.1$ & $5.2 \pm 0.4$ \\
$\begin{array}{l}\text { p-Nitrobenzaldehyde } \\
\text { Y92F }\end{array}$ & $2.0 \pm 0.3$ & $72.6 \pm 4.3$ & $35.8 \pm 3.7$ \\
Native & $5.0 \pm 0.2$ & $98.0 \pm 2.0$ & $18.9 \pm 0.4$ \\
\hline
\end{tabular}




\section{LEGENDS FOR FIGURES}

\section{Figure 1 Scheme for reactions catalyzed by AAO}

In the reductive half-reaction, AAO typically oxidizes aromatic alcohols (1) to the corresponding aldehydes (2) (top) [11;17]. However, it has been found that the enzyme can also oxidize the aromatic aldehydes (2) to the corresponding acids (4) (bottom). It is proposed that the second reaction mainly proceeds via the gem-diols (3) formed by aldehyde hydration. In both cases, $\mathrm{H}_{2} \mathrm{O}_{2}$ is generated by $\mathrm{O}_{2}$ reduction during $\mathrm{FAD}$ regeneration (oxidative half-reaction). Under natural conditions $\mathrm{H}_{2} \mathrm{O}_{2}$ is continuously generated by $\mathrm{AAO}$ in the redox cycling of benzylic fungal metabolites (alcohols, aldehydes and acids), also involving myceliar dehydrogenases [10;39].

Figure 2 Aldehyde (open triangles) and $\mathrm{H}_{2} \mathrm{O}_{2}$ (black circles) produced during $\mathrm{AAO}$ oxidation of $p$-anisyl (a) and 3-chloro-p-anisyl (b) alcohols

Alcohols $(16 \mu \mathrm{M})$ were incubated with AAO $(0.01 \mu \mathrm{M})$ for $500 \mathrm{~s}$ and the concentrations of the reductive and oxidative half-reaction products were estimated spectrophotometrically (aldehyde maxima at 295 and $285 \mathrm{~nm}$ for 3-chloro-p-anisaldehyde and $p$-anisaldehyde respectively) and by the coupled $\mathrm{H}_{2} \mathrm{O}_{2}$-dependent oxidation of Amplex ${ }^{\circledR}$ Red by HRP. The arrows indicate the addition of enzyme.

Figure 3 GC-MS of underivatized (a) and silylated (b) reactions of AAO with $p$ nitrobenzaldehyde: Chromatographic profiles (including controls, dashed lines), and mass spectra of the aldehyde substrate (peak 1) and the acid product in its free and trimethylsilyl (TMSi) ester forms (peaks 2 and 2', respectively)

p-Nitrobenzaldehyde $(4 \mathrm{mM})$ was incubated with $\mathrm{AAO}(0.3 \mu \mathrm{M})$ in $0.1 \mathrm{M}$ phosphate, $\mathrm{pH} 6$, for $3 \mathrm{~h}$ at $24{ }^{\circ} \mathrm{C}$. The reaction mixture, and the corresponding control without enzyme, were extracted and analyzed by GC-MS before (a) and after silylation (b). The mass spectra were obtained with an iontrap detector. The small peak with retention time around 19 min in $\mathbf{b}$ could be a dimeric reaction product. Silylation resulted in sharper acid peaks due to formation of more volatile ester derivatives. However, the recovery of the different acids was higher when the samples were analyzed directly, most probably because of incomplete derivatization or side-reactions in some cases.

\section{Figure 4 NMR analysis of $p$-anisaldehyde (a) and p-nitrobenzaldehyde (b) hydration}

Aldehyde solutions in $0.1 \mathrm{M}$ phosphate, $\mathrm{pH} 6$ (prepared with $\mathrm{D}_{2} \mathrm{O}$ ), were analyzed by ${ }^{1} \mathrm{H}-\mathrm{NMR}$ yielding signals corresponding to: $\mathrm{H}_{\alpha}$ in the aldehyde $(\alpha)$ and gem-diol $\left(\alpha^{\prime}\right) ; \mathrm{H}_{2,6}$ in the aldehyde (2+6) and gem-diol (2'+6'); $\mathrm{H}_{3,5}$ in the aldehyde $(3+5)$ and gem-diol $\left(3^{\prime}+5^{\prime}\right)$; and $\mathrm{H}_{\mathrm{MeO}}(\mathrm{MeO})$. For estimating the hydration rate the $\alpha^{\prime}$ signal of the gem-diol was integrated and referred to the $\alpha$ signal of the aldehyde. Similar results were obtained by referring the signals of aromatic protons in the gem-diol forms $\left(2^{\prime}+6^{\prime}\right.$ or $\left.3^{\prime}+5\right)$ to those of the corresponding protons in the aldehyde forms $(2+6$ or $3+5$ respectively).

Figure 5 Spectral changes during AAO turnover with $p$-nitrobenzaldehyde showing that the reductive half-reaction is limitant

An aerobic solution of $6.3 \mu \mathrm{M}$ AAO was mixed in the stopped-flow spectrophotometer with $2 \mathrm{mM} \mathrm{p}$ nitrobenzaldehyde in $0.1 \mathrm{M}$ phosphate, $\mathrm{pH} 6$, at $24^{\circ} \mathrm{C}$, and spectra were acquired with a diode-array detector. The oxidized AAO spectrum before mixing is indicated as a dashed line. Spectra recorded after $0.019,10,20,30,40,50,60,70,76,79,84,87,102,150,199,300$ and $400 \mathrm{~s}$ are shown. The 
inset shows the time evolution of 462-nm absorbance, revealing that the enzyme was fully oxidized under steady-state oxidation of the aldehyde.

\section{Figure 6 Spectral course of anaerobic reduction of AAO with two different aldehydes}

AAO $(\sim 8 \mu \mathrm{M})$ reduction with $0.5 \mathrm{mM}$ p-anisaldehyde $(\mathrm{a})$, and $2.0 \mathrm{mM} p$-nitrobenzaldehyde $(\mathrm{d})$, in 0.1 $\mathrm{M}$ sodium phosphate, $\mathrm{pH} 6$, at $24{ }^{\circ} \mathrm{C}$, was monitored using a diode-array stopped-flow spectrophotometer under anaerobic conditions. The initial AAO spectrum, and the first spectrum after mixing with the aldehydes are shown as dashed and dotted lines, respectively. Spectra were recorded at different times after aldehyde addition: a) after $0.5,1,13,29,52,76,102,128,152,176$, 202,301 , and $404 \mathrm{~s}$; and b) after 0.009, 0.16, 0.5, 0.8, 1.5, 20, 50, 100 and $130 \mathrm{~s}$. Insets show a deconvolution of the spectral changes during $A A O$ reduction fitting to a two step model $(A \rightarrow B)$ in $\mathbf{a}$, while the process in $d$ is better described by a three steps model $(A \rightarrow B \rightarrow C)(A, B$ and $C$ are spectral species, reflecting distribution of reactants, intermediates or products, and do not necessarily represent distinct enzyme intermediates). A comparison of kinetics traces at $462 \mathrm{~nm}$ during AAO reduction with the two aldehydes is also included (c). 

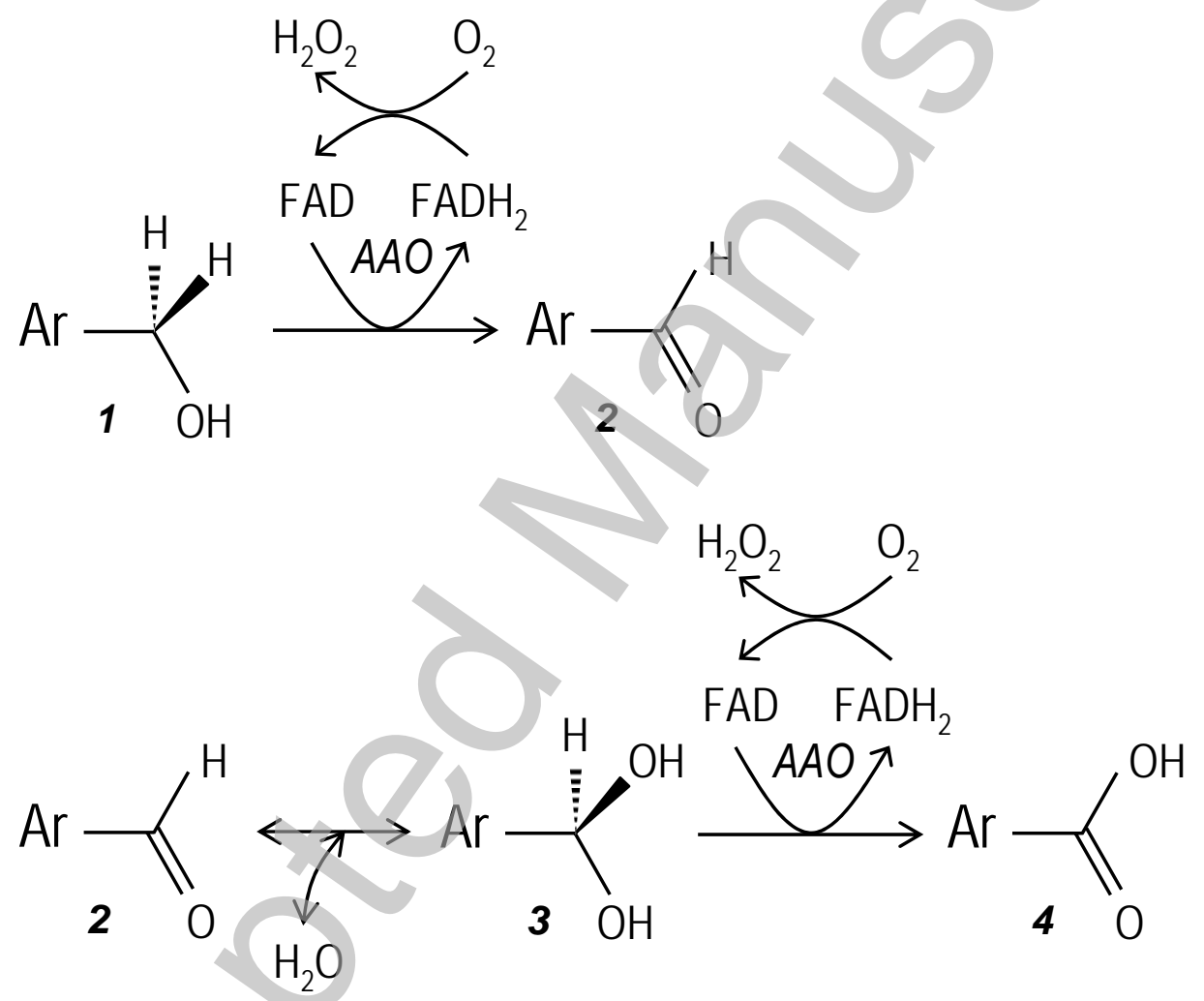

Fig 1 

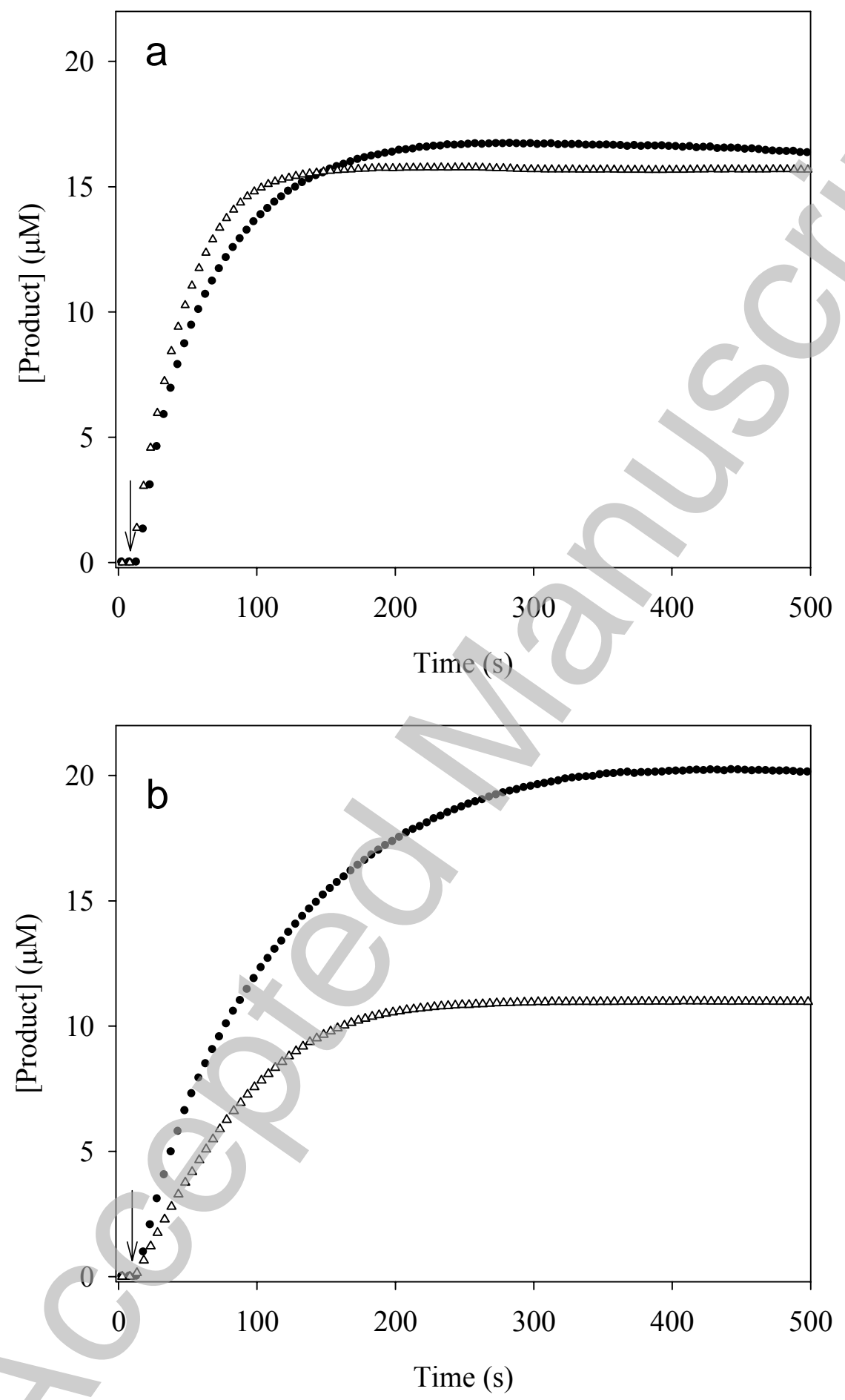

Fig 2 

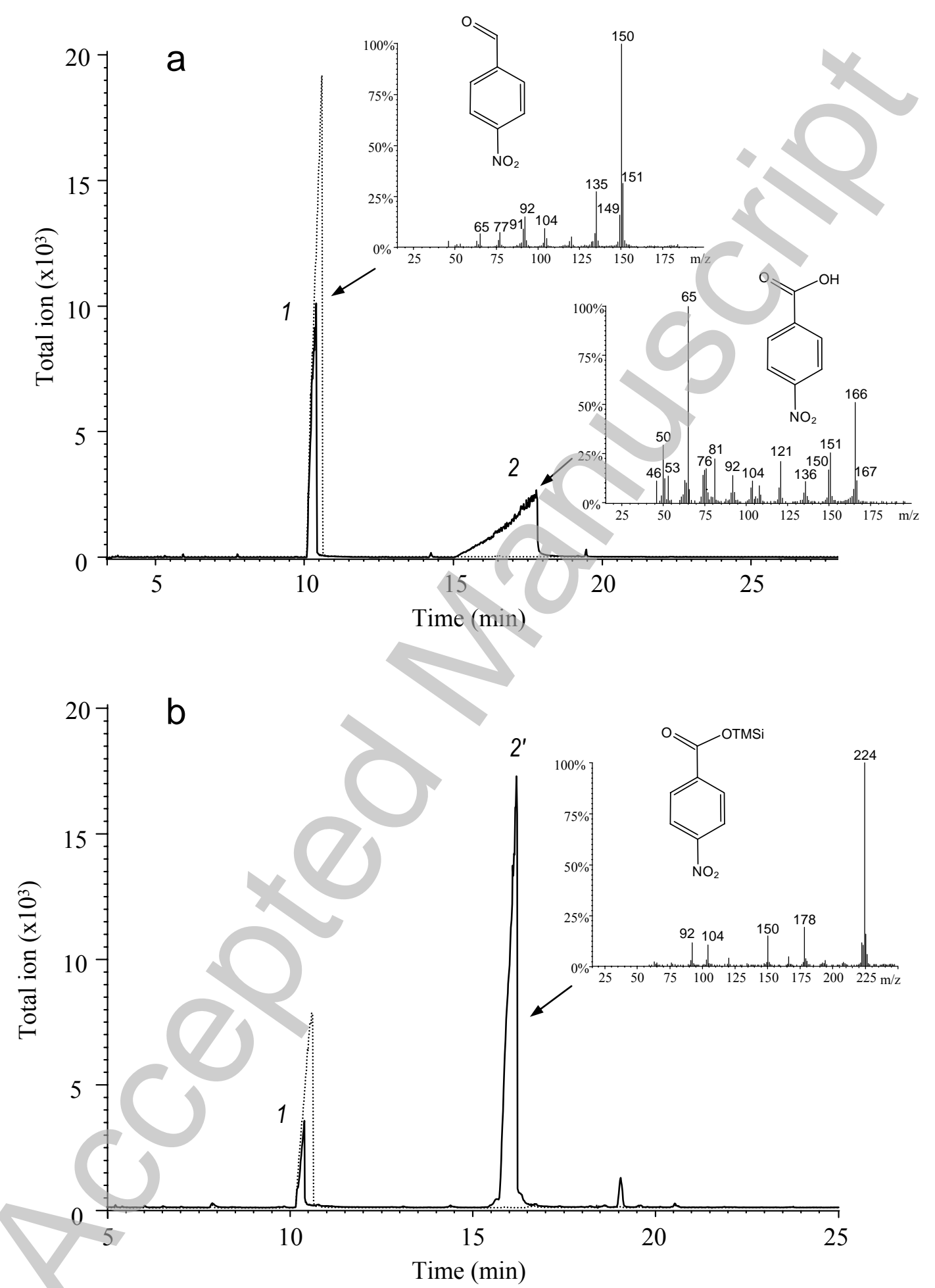

Fig 3 

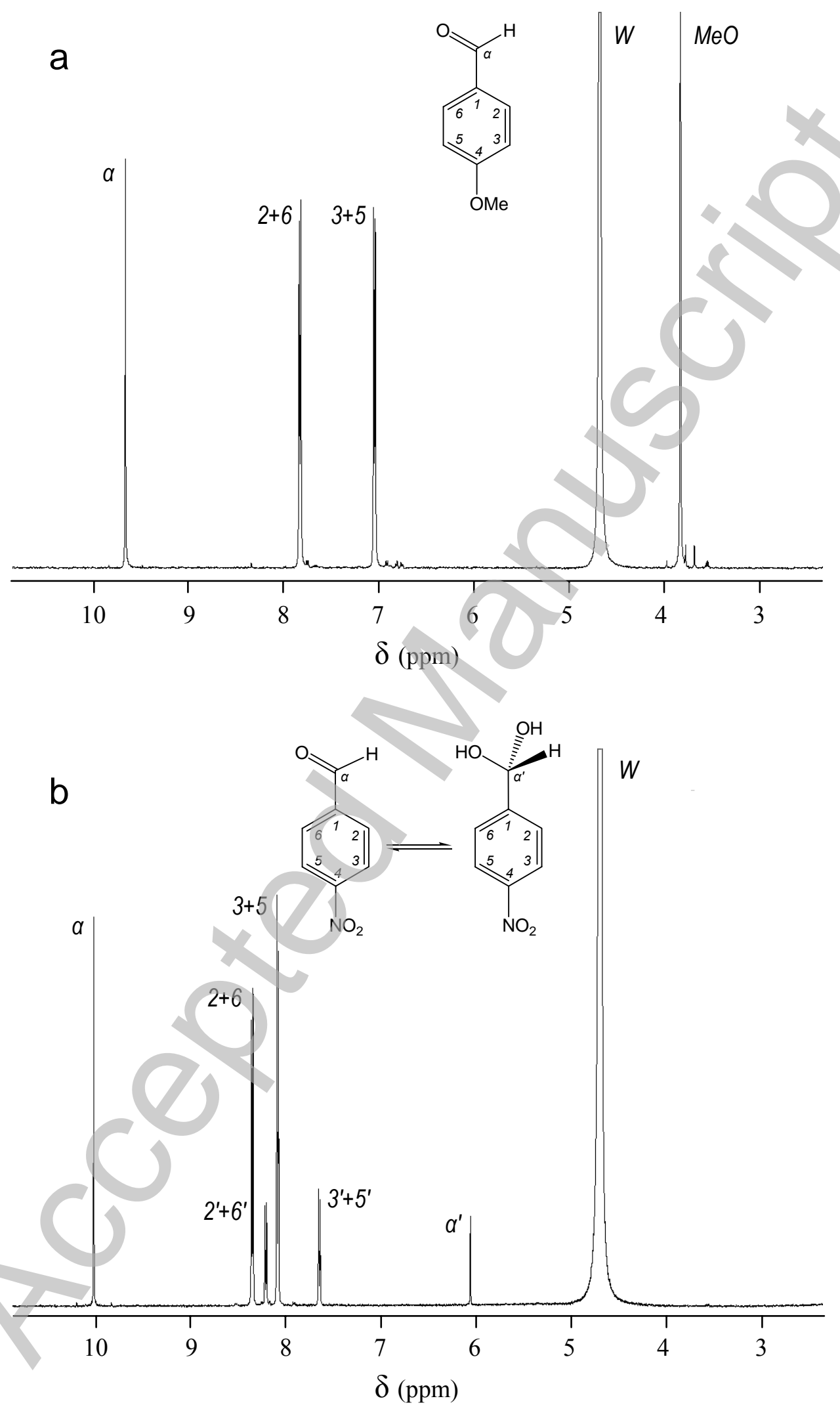

Fig 4 


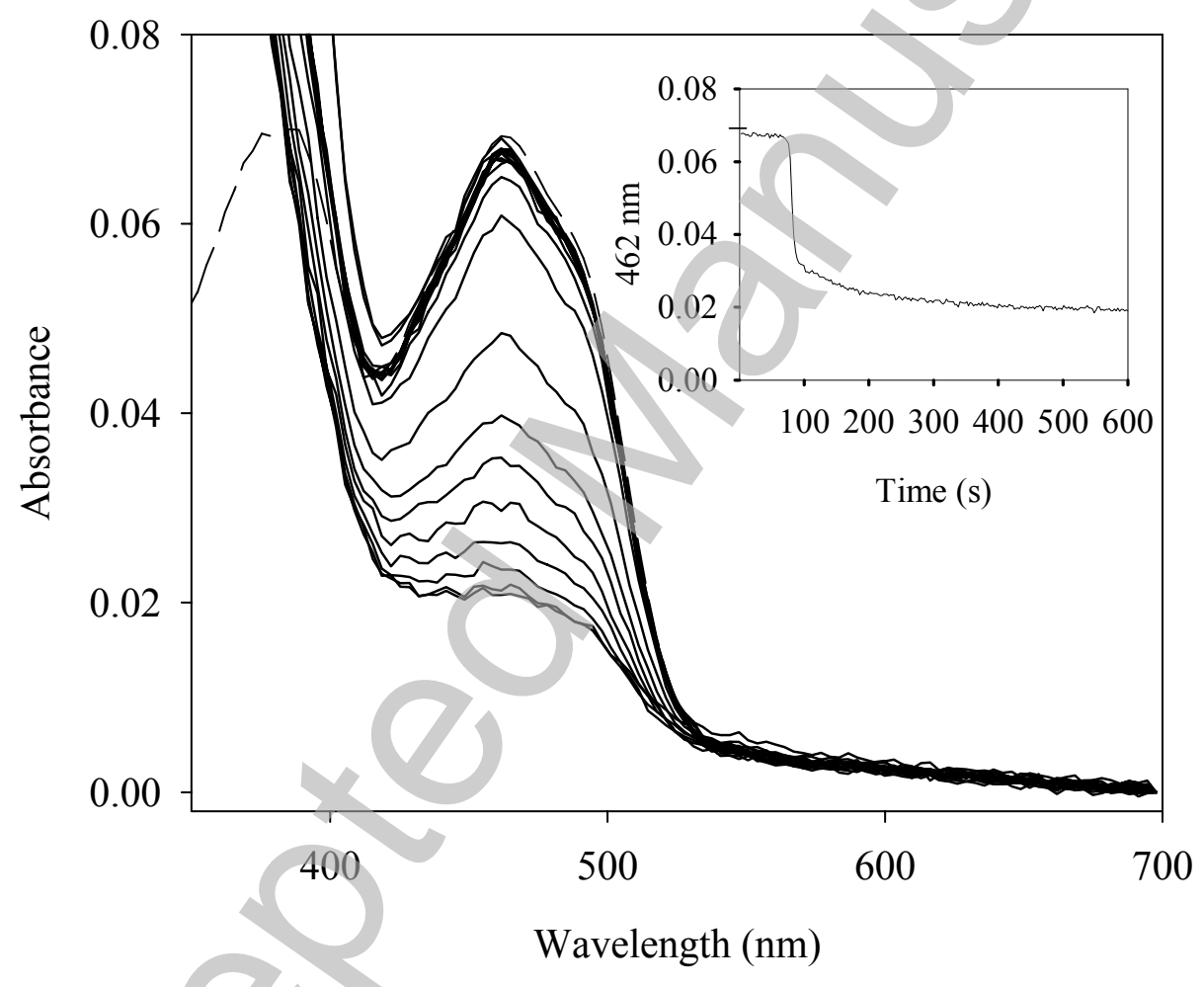

Fig 5 

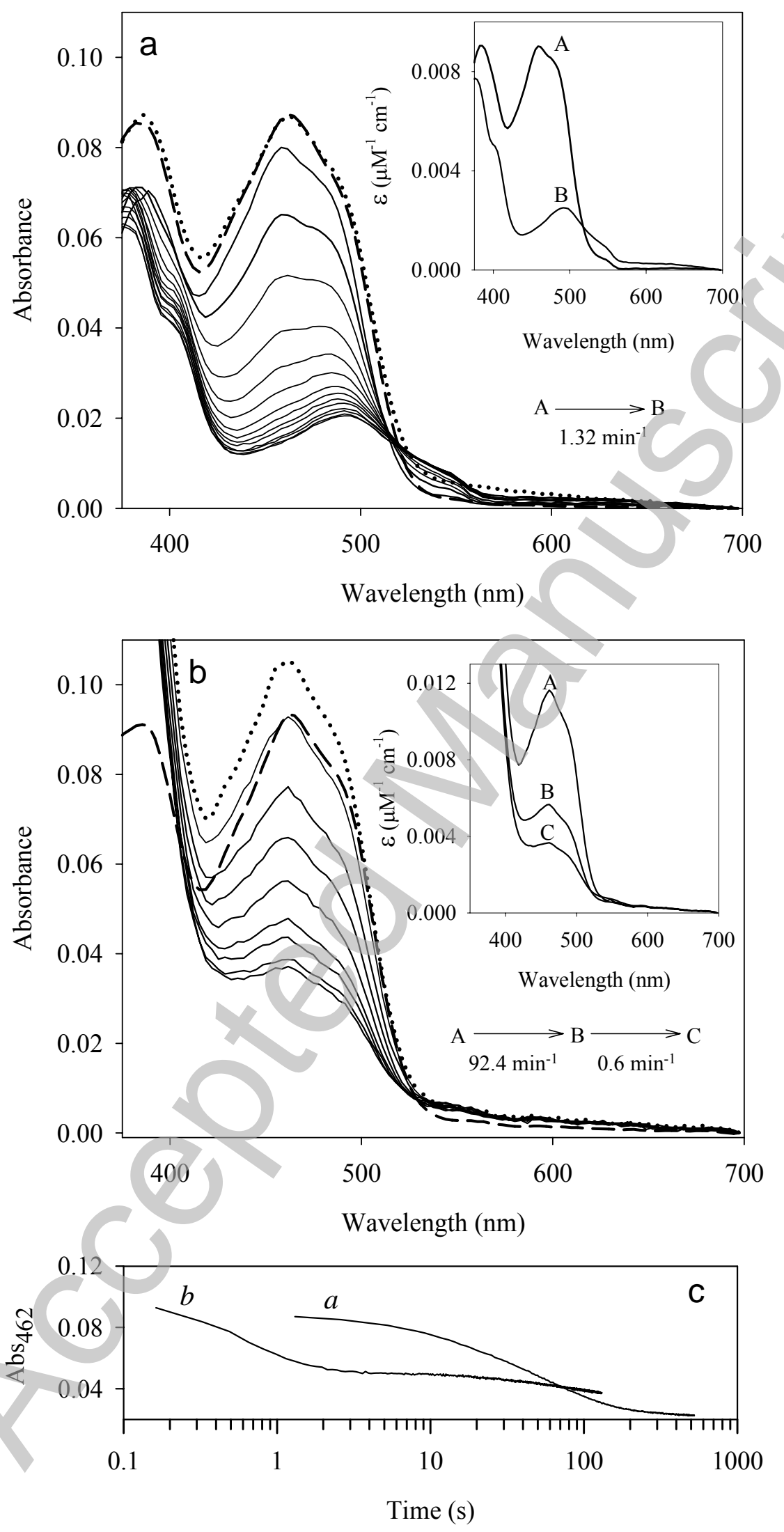

Fig 6 